\title{
搭亲子探究之桥梁 拓儿童探究之时空
}

BBuild the bridge of parent-child inquiry to expand the space and time of children's inquiry

$$
\begin{aligned}
& \text { 刘燕 } \\
& \text { Yan liu }
\end{aligned}
$$

宁波市北仑区蔚斗小学 中国・浙江 宁波 315803

Weidou Primary School, Beilun District, Ningbo, Zhejiang, 315803, China

\begin{abstract}
摘 要: 探究式学习是学生学习科学的重要方式,课堂上短短的 40 分钟,并不能真正满足孩子对探究的时空需求。开展亲 子探究成了当下较流行的拓宽儿童探究时空的有效方式。它不仅能激发孩子和家长的探究兴趣, 加深对科学知识的理解, 养 成良好的探究习惯和能力,提高科学素养,也便于促进亲子双方,家校双方更好地合作和交流。
\end{abstract}

\begin{abstract}
Inquiry-based learning is an important way for students to learn science. The short 40 minutes in class can not really meet the space-time needs of children to explore. The development of parent-child inquiry has become a popular and effective way to broaden the time and space of children's inquiry. It can not only stimulate children and parents' interest in exploration, deepen their understanding of scientific knowledge, develop good exploration habits and abilities, and improve scientific literacy, but also facilitate the better cooperation and communication between parents and children, and between parents and schools.
\end{abstract}

关键词: 亲子探究;桥梁; 主体; 价值; 时空;科学素养

Keywords : parent-child inquiry ; bridge ; principal value; space-time; scientific literacy

DOI : $10.36012 /$ sde. v3i2. 2943

小学生正处于学好科学知识和养成良好探究精神的关 键时期,其科学素养的高低不仅仅影响到个人未来的发展好 坏, 更关系着一个国家的整体素质。小学科学课程的学习方 式多种多样, 探究式学习是学生学习科学的重要方式。但是 课堂上短短的 40 分钟, 并不能真正满足孩子对探究的时空 需求,开展亲子探究成了当下较流行的拓宽儿童探究时空的 有效方式。据国内外有关研究表明,父母对探究的参与积极 性极大程度上影响着孩子参与探究的热情。可见,搭建亲子 探究的“桥梁”不仅成为一种流行, 更成为一种需要。如何搭 建亲子探究的坚固桥梁,促进夯实儿童探究之根基、养成探 究之习惯、获得探究之兴趣、体会探究之乐趣, 提升探究之素 养,笔者认为要做好以下几个方面……

\section{1 桥之梁,建亲子探究主体之境}

科学探究有家长的参与本是一件好事, 但容易出现一旦 家长加人, 探究的“主体”就会发生变化, 家长取而代之, 甚至 一手包办, 到最后孩子成了旁观者。其实, 不管是课堂探究
还是家庭探究, 其主体都应该是孩子, 而不是老师或家长。 在亲子探究的过程中, 家长和老师要做的是为孩子创建主动 探究的情境,发挥其引导, 组织, 促进之作用。

\section{情境一:探究过程“精准分析”}

当确定探究内容后, 家长和老师应该做些什么? “精准分析”探究过程中孩子可能会遇到的困难,思考如何引 导和解决,即对探究中可能会出现的问题保持高度敏感。因 为小学生往往在遇到自己无法解决的困难时会习惯选择放 弃, 从而渐渐降低对探究的兴趣。

例如曾有一个一年级的学生和父母一起开展一个家庭 实验:《制作一个会转的小天鹅》, 其过程是利用铜丝, 磁铁, 电池等物品利用电磁原理制作一个会转的铜丝制品, 在制作 的过程中,出现的最大的困难是小天鹅不会转,为什么不会 转,家长分析了很多原因, 而且还和科学教师交流, 一起讨 论,最后在各种改进下,终于成功了,其实对一年级的孩子来 说,这场探究最大的难点是两个: (1)技能层面: 用钢丝拗一个 “小天鹅”,特别是绕线圈那部分; (2)知识层面: 当出现“小天

【作者简介】刘燕 (1985 ) , 女, 汉, 学历大学本科, 浙江宁波人, 小学教师, 学士。 
我” 不会转时,如何引导孩子分析原因并验证。针对第一个 难点, 当时孩子的爸爸就直接帮孩子完成这一步, 笔者觉得 相比家长直接帮孩子做一个, 更好的做法应该是家长先研究 用什么办法或者工具可以降低孩子绕线圈的难度,例如可以 引导孩子用一支笔或者圆柱形的物体绕线圈, 这样的做法, 家长既没有剥夺孩子自己动手的机会, 而且也无形中教育孩 子如何借助其它物体解决问题的意识, 这才是以孩子为主体 的情境。当出现第二个难点 “小天鹅” 不会转时, 相比家长直 接百度或者联系老师, 由家长和老师主导分析原因并验证的 做法, 更科学的做法应该是家长先引导孩子自己分析原因, 其实孩子并不是完全不会分析原因, 因为至少孩子认识磁 铁, 孩子熟悉电池, 最起码孩子会提出不会转是不是电池没 电等常见的想法。如果家长为了追求实验完成的效率忽略 了孩子的思考过程, 其实倒不如放慢速度,让孩子提出猜想 并亲自验证, 直到孩子无能为力解决问题时, 家长再带着孩 子一起咨询老师或百度, 也可以让孩子自己咨询, 而不是家 长自己咨询自己验证, 甚至在验证过程中为了怕验证失败而 阻止孩子“动手”, 只有创建以孩子为主体的情境, 才能真正 激发子孩子的探究欲望。

\section{2 桥之墩, 塑亲子探究价值之魂}

在亲子探究的实践和跟进中, 我对开展亲子探究的价值 定位发生了很大的变化。原来很多老师都认为开展亲子探 究的目的是希望家长能带着孩子多做实验, 在多做实验的过 程中帮助孩子学习更多的科学知识并提高探究的兴趣和能 力。现如今, 经过亲身实践和持续地跟进关注, 我发现开展 亲子探究的真正价值不在于家长带着孩子做了多少个实验, 获得了多少科学知识, 而是在探究的过程中培养孩子发现问 题、解决问题的意识和能力,让孩子在思考问题、分析问题、 解决问题的过程中培养探究兴趣, 了解科学知识, 形成良好 的科学探究能力和探究精神。

\section{3 桥之引, 导亲子探究时空之向}

经实践发现, 面对亲子探究, 家长的顾虑主要有三点: (1) 担心自己工作忙材料准备麻烦; (2)担心孩子学业任务重没 时间 (3)不知道探究什么。孩子的顾虑也主要有三点: (1)担 心作业太多没时间 (2)担心实验太难不会做; (3)担心爸爸妈 妈没时间陪伴。可见, 在有限的时空里, 如何引导家长和孩 子开展亲子探究非常重要。

倡导一:多样化的探究形式

在很多家长和孩子的眼里, 亲子探究就是买材料做实
验。其实,科学素养包括多个维度, 不同的素养要通过不同 的探究形式加以培养。除了在家做实验, 戏剧表演、科学游 戏、模型制作、外出参观考察等都是亲子探究的有效形式。 为了促进孩子科学素养的多维度发展, 我们应该引导家长和 孩子开展多形式的探究,这不仅有助于减轻他们对亲子探究 的“顾虑”, 还可以帮助家长和孩子在多样化的探究中发现其 乐趣和价值。

\section{倡导二:弹性化的探究时间}

相比课堂探究, 亲子探究的时间比较自由, 考虑到家长 和孩子对探究时间的顾虑, 我们可以引导家长和孩子结合探 究的形式弹性选择探究时间。这样家长和孩子可以根据学 业任务及居家生活合理安排探究时间。

倡导三:专业化的探究指导

经实践发现,很多父母面对亲子探究,普遍表现出对自 身科学素养不自信, 对自身角色定位不清晰, 与孩子沟通交 流有障碍等各种问题。究其原因主要是家长对亲子探究的 认识不不专业。所以专业化的指导显得无为重要。教师可 以推荐优秀的探究资源,如书籍,媒体, 平台等, 让家长有径 可寻,有理可据。当探究过程中出现家长无法解决的问题 时, 应引导家长和孩子主动联系教师, 及时咨询, 科学分析, 有效解决。

倡导四:信息化的探究宣传

实践发现, 真正会主动开展亲子探究的家庭不多, 需要 学校, 教师从中大力宣传和鼓励。学校也可以在亲子探究开 展过程中借学校微信公众号大力宣传优秀的亲子探究案例, 并积极采用各种评价机制如科学小明星, 探究型家庭评选等 促进更多家庭参与。通过活动宣传力度的加大, 引发了更加 家庭的关注和参与。

\section{4 亲子探究的实践再思考}

开展亲子探究课程, 目的是希望家长能带着孩子一起探 究科学, 因为亲子探究不仅能激发孩子和家长的探究兴趣, 加深对科学知识的理解, 养成良好的探究习惯和能力, 提高 科学素养, 也便于促进亲子双方, 家校双方更好地合作和交 流。同时亲子探究对一个科学老师自身的科学教学也有一 定的帮助,因为策划、指导亲子探究的过程本身就是一种相 互促进、学习和研究。

\section{参考文献}

[1] 《温州市亲子科学探究活动实践调查》

[2]《小学科学课程标准》 